\title{
Drosophila Graf regulates mushroom body $\beta$-axon extension and olfactory long-term memory
}

\author{
Sungdae Kim', Joohyung Kim², Sunyoung Park ${ }^{1}$, Joong-Jean Park ${ }^{3}$ and Seungbok Lee ${ }^{{ }^{*}}$ (D)
}

\begin{abstract}
Loss-of-function mutations in the human oligophrenin-1 (OPHN1) gene cause intellectual disability, a prevailing neurodevelopmental condition. However, the role OPHN1 plays during neuronal development is not well understood. We investigated the role of the Drosophila OPHN1 ortholog Graf in the development of the mushroom body (MB), a key brain structure for learning and memory in insects. We show that loss of Graf causes abnormal crossing of the MB $\beta$ lobe over the brain midline during metamorphosis. This defect in Graf mutants is rescued by MB-specific expression of Graf and OPHN1. Furthermore, MB a/ $\beta$ neuron-specific RNA interference experiments and mosaic analyses indicate that Graf acts via a cell-autonomous mechanism. Consistent with the negative regulation of epidermal growth factor receptor (EGFR)-mitogen-activated protein kinase (MAPK) signaling by Graf, activation of this pathway is required for the $\beta$-lobe midline-crossing phenotype of Graf mutants. Finally, Graf mutants have impaired olfactory long-term memory. Our findings reveal a role for Graf in MB axon development and suggest potential neurodevelopmental functions of human OPHN1.
\end{abstract}

Keywords: Drosophila, Intellectual disability, Graf/oligophrenin-1, EGFR signaling, Mushroom body development

\section{Introduction}

Intellectual disability (ID) is a neurodevelopmental disorder defined by significant impairments in both intellectual functioning and adaptive behavior that affects approximately $1 \%$ of the global population [1]. The underlying causes of ID are highly heterogeneous, including environmental factors and/or genetic changes affecting 1000 genes [2]. The human oligophrenin-1 (OPHN1) gene was first associated with ID by molecular analysis of an X;12 balanced translocation in a patient [3, 4]. Subsequently, several loss-of-function mutations in OPHN1 have been found in families with syndromic ID associated with cerebellar hypoplasia and, in some cases,

*Correspondence: seunglee@snu.ac.kr

${ }^{1}$ Department of Cell and Developmental Biology and Dental Research Institute, Seoul National University, Seoul 08826, Republic of Korea

Full list of author information is available at the end of the article with ventricular dilation [5-8]. Ophn1 deficiency in mice recapitulates some of the human pathologies including behavioral and cognitive abnormalities, as well as ventricular dilation [9], supporting the notion that loss of $O P N H 1$ function is responsible for syndromic ID.

The OPHN1 protein belongs to the Graf (GTPase regulator associated with focal adhesion kinase-1) subfamily of GTPase-activating proteins (GAPs), whose members commonly comprise an N-terminal Bin/amphiphysin/ Rvs (BAR) domain, a pleckstrin homology (PH) domain, and a RhoGAP domain [10]. Whereas other Graf subfamily members (GRAF1, GRAF2, and GRAF3) contain a C-terminal Src homology 3 (SH3) domain, OPHN1 possesses a proline-rich domain. The BAR and $\mathrm{PH}$ modules of OPNH1 produce or sense membrane curvature [11], and the GAP domain inhibits Rho-family small GTPases, the master regulators of actin dynamics $[3,12$, 13]. The proline-rich domain of OPHN1 interacts with original author(s) and the source, provide a link to the Creative Commons licence, and indicate if changes were made. The images or other third party material in this article are included in the article's Creative Commons licence, unless indicated otherwise in a credit line to the material. If material is not included in the article's Creative Commons licence and your intended use is not permitted by statutory regulation or exceeds the permitted use, you will need to obtain permission directly from the copyright holder. To view a copy of this licence, visit http://creativecommons.org/licenses/by/4.0/. The Creative Commons Public Domain Dedication waiver (http://creativeco mmons.org/publicdomain/zero/1.0/) applies to the data made available in this article, unless otherwise stated in a credit line to the data. 
the endocytic protein endophilin $[14,15]$, suggesting that OPHN1 may regulate endocytosis by orchestrating actin and membrane dynamics. OPHN1 is highly expressed in the brain and localizes to neuronal pre- and postsynaptic compartments [13]. Postsynaptic OPHN1 regulates synaptic structure, function, and plasticity by controlling $\quad \alpha$-amino-3-hydroxy-methylisoazol-4-propionate (AMPA) receptor internalization and/or stability [9, $13,16,17]$, whereas presynaptic OPHN1 is required for efficient synaptic vesicle endocytosis $[15,16]$. Both of these functions appear to involve OPHN1's GAP activity toward RhoA and interactions with endophilin A1 [13, 15-17]. Precise regulation of Rho-GTPase signaling is also important for neurite outgrowth and axon pathfinding during neuronal development [18]. However, it is not known whether the RhoGAP protein OPHN1 plays additional roles in the developing nervous system.

The Drosophila genome contains a single ortholog of the human Graf gene family (Graf). The Drosophila Graf protein has an identical domain organization (except its C-terminal SH3 domain) and displays 33\% identity and $50 \%$ similarity to human OPHN1 [19]. In this study, we characterized the role of Graf in the developing mushroom body $(\mathrm{MB})$, which is a key brain structure for olfactory learning and memory in insects [20] and is an excellent model for the study of gene functions in neuronal development. We show that Graf is required for MB $\beta$-lobe axons to stop at the brain midline. Expression pattern and mosaic analyses demonstrate that Graf acts via a cell-autonomous mechanism, and genetic interaction experiments suggest that Graf regulates $\beta$-lobe axon extension by downregulating the epidermal growth factor receptor (EGFR)-mitogen-activated protein kinase (EGFR-MAPK) pathway. Finally, we show that Graf is required for the formation of olfactory long-term memory. Altogether, our results define a role for Graf in establishing neuronal wiring patterns and may contribute to a better understanding of the pathogenesis of OPHN1induced ID.

\section{Materials and methods Drosophila strains}

Flies were maintained on standard Drosophila yeastcornmeal molasses food at $25{ }^{\circ} \mathrm{C}$. The wild-type strain used in this study was $w^{1118}$. The Graf null mutant, Graf ${ }^{1}$, and transgenic UAS-Graf-HA flies were described previously [19]. Transgenic lines carrying Graf-GAL4 and UAS-OPHN1-HA were generated in the $w^{1118}$ background by standard procedures. The following fly strains were obtained from the Bloomington Stock Center (Bloomington, IN, USA): Df(1)BSC756 (a deficiency of the Graf locus), UAS-Graf ${ }^{R N A i}, E g f r^{f 24}, \mathrm{rl}^{1}$, UAS-mCD8GFP, UAS-NLS-mCherry, and UAS-EGFR ${ }^{C A} \cdot r^{10}$ was obtained from Ernst Hafen (ETH Zurich, Switzerland). The following GAL4 lines were used as drivers of upstream activation sequence (UAS) transgenes: C155GAL4 [21], OK107-GAL4 [22], c739-GAL4, c305a-GAL4, and 1471-GAL4 [23]. The following fly strains for mosaic analysis with a repressible cell marker (MARCM) of MB neurons were obtained from the Bloomington Stock Center: FRT19A and hs-FLP,tubP-GAL80,FRT19A/Y; UAS-mCD8-GFP/CyO; OK107-GAL4.

\section{MARCM-based clonal analysis}

To generate mitotic single cell clones in the MB, we used the MARCM technique as described previously [24]. To produce green fluorescent protein (GFP)labeled wild-type and Graf mutant clones, hs-FLP,tubPGAL80,FRT19A/Y; UAS-mCD8-GFP/CyO; OK107-GAL4 flies were crossed to either FRT19A or Graf ${ }^{1}, F R T 19 A$ flies. The MARCM-ready animals were subjected to heat shock $\left(37^{\circ} \mathrm{C}\right.$ for $\left.40 \mathrm{~min}\right)$ at the pupal stage. Female adult brains were stained with anti-GFP and anti-FasII antibodies to label MARCM clones and the $\alpha / \beta$-lobe area. Fifteen brains were examined for marked MB clones.

\section{Molecular biology}

For generation of a Graf-GAL4 driver, a 4697 bp fragment of the Graf $5^{\prime}$ region ( -4967 to +1 relative to the translation starting site) was PCR amplified from the genomic clone BACR23C18 (Children's Hospital Oakland Research Institute, Oakland, CA, USA) and inserted into the pCaspeR4 vector (Addgene, Watertown, MA, USA). Subsequently, the GAL4 gene and the Drosophila hsp70 terminator were excised from the pGaTB vector [25] and subcloned into the $3^{\prime}$ end of the Graf promoter.

For transgenic rescue experiments, the full-length cDNA of human OPHN1 was amplified by reverse transcription PCR (RT-PCR) of total RNA prepared from HeLa cells and then inserted into pGEM-T Easy vector (Promega, Madison, WI, USA). The human OPHN1 cDNA insert was subcloned into the pcDNA3.1-HA vector, a derivative of the pcDNA3.1 $(+)$ vector (Invitrogen, Carlsbad, CA, USA), and then moved with the corresponding hemagglutinin (HA) tag into the pUAST vector to produce $U A S-O P H N 1-H A$.

For RNA interference experiments in BG2-c2 cells, Graf double-stranded RNA (dsRNA) was generated by in vitro transcription of a DNA template containing the T7 promoter sequence at both ends, as previously described [26]. The DNA template was PCR-amplified from $U A S-G r a f-H A$ using primers containing the T7 promoter sequence upstream of the following Graf-specific sequences: 5'-AATTTGAGTGCGATGAAGTTC-3' and 5'- ATTTCAACATTCTACGTTTTC-3'. The efficiency of Graf knockdown was confirmed by RT-PCR analysis 
using the following primers: 5'-GCAAACGCAAACATC ATGGGC- $3^{\prime}$ and $5^{\prime}$-GAGTGGACAGGATCTTTGCCG$3^{\prime}$ for Graf, and 5'-CACCAGTCGGATCGATATGC-3' and $5^{\prime}$-CACGTTGTGCACCAGGAACT-3' for $r p 49$.

\section{Brain dissection and immunostaining}

Brains from pupae or 2-day-old adults were dissected in ice-cold phosphate-buffered saline (PBS) and fixed in PBS containing $4 \%$ formaldehyde for $30 \mathrm{~min}$. Fixed brains were washed three times for 20 min each with PBS containing $0.3 \%$ Triton X-100, and blocked in PBS containing $0.3 \%$ Triton X-100 and $0.2 \%$ bovine serum albumin for $30 \mathrm{~min}$. Samples were sequentially incubated with primary antibodies in blocking buffer for $48 \mathrm{~h}$ at $4{ }^{\circ} \mathrm{C}$ and with fluorescently labeled secondary antibodies overnight at $4{ }^{\circ} \mathrm{C}$. The following primary antibodies were used: mouse anti-FasII (1D4, 1:10; Developmental Studies Hybridoma Bank, Iowa City, IA, USA), rabbit anti-phospho-ERK (1:500; Cell Signaling Technology, Danvers, MA, USA), and rabbit anti-GFP (1:1000; Invitrogen). FITC- and Cy3-conjugated secondary antibodies were purchased from Jackson ImmunoResearch (West Grove, PA, USA) and used at a dilution of 1:200. Images were captured with either an LSM 800 laser-scanning confocal microscope (Carl Zeiss, Jena, Germany) using a Plan Apo $20 \times / 0.8$ objective lens or an FV300 laserscanning confocal microscope (Olympus, Tokyo, Japan) using a Plan Apo $10 \times / 0.45$ or Plan Apo $20 \times / 0.80$ objective lens.

\section{Western blotting}

Brains from 2-day-old adults were homogenized in sodium dodecyl sulfate (SDS) sample buffer $(62.5 \mathrm{mM}$ Tris- $\mathrm{HCl}, \mathrm{pH} 6.8,10 \%$ glycerol, $2 \%$ SDS, $2.88 \mathrm{mM}$ $\beta$-mercaptoethanol, and $0.02 \%$ bromophenol blue). Samples were boiled for $5 \mathrm{~min}$ and centrifuged at 13,000 g for $10 \mathrm{~min}$. Supernatants were subjected to $10 \%$ SDS-PAGE and then transferred to polyvinylidene fluoride membrane (Merck Millipore, Burlington, MA, USA). Blots were incubated overnight at $4{ }^{\circ} \mathrm{C}$ with rabbit anti-phospho-ERK (1:1000, Cell Signaling Technology) or rabbit anti-ERK (1:1000, Cell Signaling Technology), and then for $1 \mathrm{~h}$ at $25^{\circ} \mathrm{C}$ with HRP-conjugated secondary antibody (1:5000; Jackson ImmunoResearch) in blocking solution (5\% skim milk/0.1\% Tween-20/Tris-buffered saline). Protein bands were detected using ECL reagents (iNtRON Biotechnology, Seongnam, Republic of Korea).

\section{Cell transfection}

Drosophila neuronal BG2-c2 cells (DGRC, Bloomington, IN, USA) were maintained at $25{ }^{\circ} \mathrm{C}$ in Shields and Sang M3 insect medium (Sigma-Aldrich, St. Louis, MO, USA) supplemented with $10 \%$ heat-inactivated fetal bovine serum (Gibco, Carlsbad, CA, USA) and $10 \mu \mathrm{g} /$ $\mathrm{ml}$ insulin (Sigma-Aldrich). Drosophila S2R + cells were maintained at $25^{\circ} \mathrm{C}$ in Schneider's medium (Gibco) supplemented with $10 \%$ heat-inactivated fetal bovine serum. Cells were transfected in serum-free medium using Cellfectin II (Invitrogen), according to the manufacturer's instructions.

\section{EGFR internalization assay}

BG2-c2 cells were transfected with UAS-Flag-EGFR and actin-C5-GAL4 in the presence or absence of Graf dsRNA. At $48 \mathrm{~h}$ post-transfection, cells were starved for $6 \mathrm{~h}$ in serum-free medium and incubated with $5 \mu \mathrm{g} / \mathrm{ml}$ mouse anti-Flag antibody (Sigma-Aldrich) in serum-free medium for $1 \mathrm{~h}$ at $4{ }^{\circ} \mathrm{C}$ to label cell surface Flag-tagged EGFR proteins. After washing with serum-free medium, cells were incubated in Spitz (Spi)-conditioned medium, produced using $\mathrm{S} 2 \mathrm{R}+$ cells as described in our previous study [19], containing 0 or $10 \mathrm{ng} / \mathrm{ml} \mathrm{Spi-HA}$ for $5 \mathrm{~min}$ at $25{ }^{\circ} \mathrm{C}$ to allow for Flag-EGFR internalization. Cells were fixed in PBS containing $4 \%$ formaldehyde for $10 \mathrm{~min}$ and incubated with FITC-conjugated anti-mouse IgG secondary antibody (1:200 dilution) to label Flag-tagged EGFRs remaining on the cell surface. Cells were then washed and permeabilized with $0.2 \%$ Triton X-100 in PBS for $10 \mathrm{~min}$ and incubated with Cy3-conjugated anti-mouse IgG secondary antibody. A Z stack of optical sections $(0.35 \mathrm{um}$ thick) was taken with an LSM 800 laser-scanning confocal microscope (Carl Zeiss) using a Plan Apo $63 \times / 1.4$ oil objective lens. ImageJ software (NIH, Frederick, MD, USA) was used to measure surface and internal FlagEGFR fluorescence intensities as the integrated pixel intensities in the green and red channels, respectively. The internalization index was defined as the ratio of internalized to surface mean fluorescence intensities.

\section{Pavlovian olfactory learning and memory}

Flies were maintained on a $12 \mathrm{~h} \mathrm{light/dark} \mathrm{cycle} \mathrm{at} 25^{\circ} \mathrm{C}$. Four- to eight-day-old adult flies were subjected to a classical (Pavlovian) olfactory conditioning procedure under dim red light at $25^{\circ} \mathrm{C}$ and $70 \%$ relative humidity, as previously described [27]. Briefly, 60 flies were collected in a training chamber, the inside of which was covered with a copper grid. Flies were allowed $30 \mathrm{~s}$ to acclimate and then sequentially exposed to two odors, 3-octanol (OCT; Sigma-Aldrich) and 4-methylcyclohexanol (MCH; Sigma-Aldrich). Relative concentrations of the two odors were adjusted so that naïve untrained flies had no preference for either of them in the T-maze (see below). Flies were first exposed for $60 \mathrm{~s}$ to the conditioned stimulus $(\mathrm{CS}+$; OCT or $\mathrm{MCH})$ paired with the unconditioned stimulus (US; twelve $1.25 \mathrm{~s}$ pulses of $90 \mathrm{~V}$ electric shock delivered once every $5 \mathrm{~s}$ ). After ventilation with fresh air 
for $30 \mathrm{~s}$, flies were exposed for $60 \mathrm{~s}$ to the control stimulus ( $\mathrm{CS}-$; OCT or $\mathrm{MCH}$ ) without electric shock. The chamber was then flushed with fresh air for $30 \mathrm{~s}$. Each individual experiment consisted of two groups of 60 flies, with one group trained to $\mathrm{OCT}$ and the other group to $\mathrm{MCH}$.

Trained flies were tested in a T-maze apparatus in which the OCT and $\mathrm{MCH}$ odors were simultaneously presented to the flies from the opposite arms of the maze. The flies located in the center of the maze were allowed to move freely for $2 \mathrm{~min}$. Tested flies were trapped inside their respective T-maze arms, anesthetized, and counted. The performance index (PI) was calculated as the percentage of flies that correctly chose the CS- odor minus the percentage of flies that incorrectly chose the shockassociated CS + odor. A final PI was calculated by averaging both reciprocal PIs for the two odors.

Animals were subjected to one training session for learning, short-term $(1 \mathrm{~h})$ memory, and intermediateterm $(3 \mathrm{~h})$ memory experiments and to ten training sessions with a 15 min rest interval between each for long-term $(24 \mathrm{~h})$ memory experiments. For learning experiments, flies were immediately tested after training.

\section{Results}

\section{Graf is required for normal MB $\beta$-lobe extension}

Drosophila MBs are bilaterally symmetrical neuropil structures with their cell bodies clustered in the dorsoposterior cortex of the fly brain. At the adult stage, each $\mathrm{MB}$ is composed of three major types of neurons: $\alpha / \beta, \alpha^{\prime} / \beta^{\prime}$, and $\gamma[28]$. These neurons project their axons ventroanteriorly through a tract called the peduncle (Fig. 1a). At the anterior extremity of the peduncle, individual axons from $\alpha / \beta$ and $\alpha^{\prime} / \beta^{\prime}$ neurons bifurcate to form the dorsal $\left(\alpha\right.$ and $\left.\alpha^{\prime}\right)$ and medial $\left(\beta\right.$ and $\left.\beta^{\prime}\right)$ lobes. By contrast, $\gamma$ neurons project only to the medial $\gamma$ lobe. The lateral lobes $\left(\beta, \beta^{\prime}\right.$, and $\left.\gamma\right)$ in the adult MB terminate near the brain midline (Fig. 1a).

To investigate the roles of Drosophila Graf in MB development, we first explored its expression in the adult brain. As our polyclonal anti-Graf antibodies failed to detect endogenous Graf, we utilized UAS-mCD8-GFP (a UAS transgene of a membrane-associated mCD8-GFP) expression with a Graf promoter-GAL4 fusion (GrafGAL4). Prominent activity of Graf-GAL4 was restricted in the $\mathrm{MB}$, antennal lobe (AL), and subesophageal ganglion (SEG), as visualized by mCD8-GFP expression (Fig. 1b). Within the MB, Graf-GAL4 activity was highly specific for $\alpha / \beta$ neurons (Fig. 1b).

We next assessed the overall morphology of the MBs from adult flies transheterozygous for the Graf null allele, Graf $^{1}$ [19], and $D f(1) B S C 756$ (hereafter referred to as Df), a deficiency uncovering the Graf locus. For this, we used an antibody against the cell adhesion molecule fasciclin II (FasII) that strongly labels the $\alpha$ and $\beta$ lobes strongly and weakly labels the $\gamma$ lobe [29]. In wild-type $\left(w^{1118}\right)$ adult brains, axons in the medially projecting $\beta$ and $\gamma$ lobes terminated near the brain midline and rarely crossed it (Fig. 2a, e), as previously reported [30]. By contrast, in a majority (73\%) of $\mathrm{Graf}^{l} / \mathrm{Df}$ mutant adult brains, $\beta$-axon fibers overextended beyond the midline, such that the $\beta$ lobes from both hemispheres appeared to fuse (Fig. 2bd). When quantified according to the scoring criteria described by Michel et al. [31], the $\beta$-lobe midline crossing phenotype of $\mathrm{Graf}^{1} / \mathrm{Df}$ mutant brains was categorized as mild (13\%), moderate (7\%), or severe (53\%) (Fig. 2e).

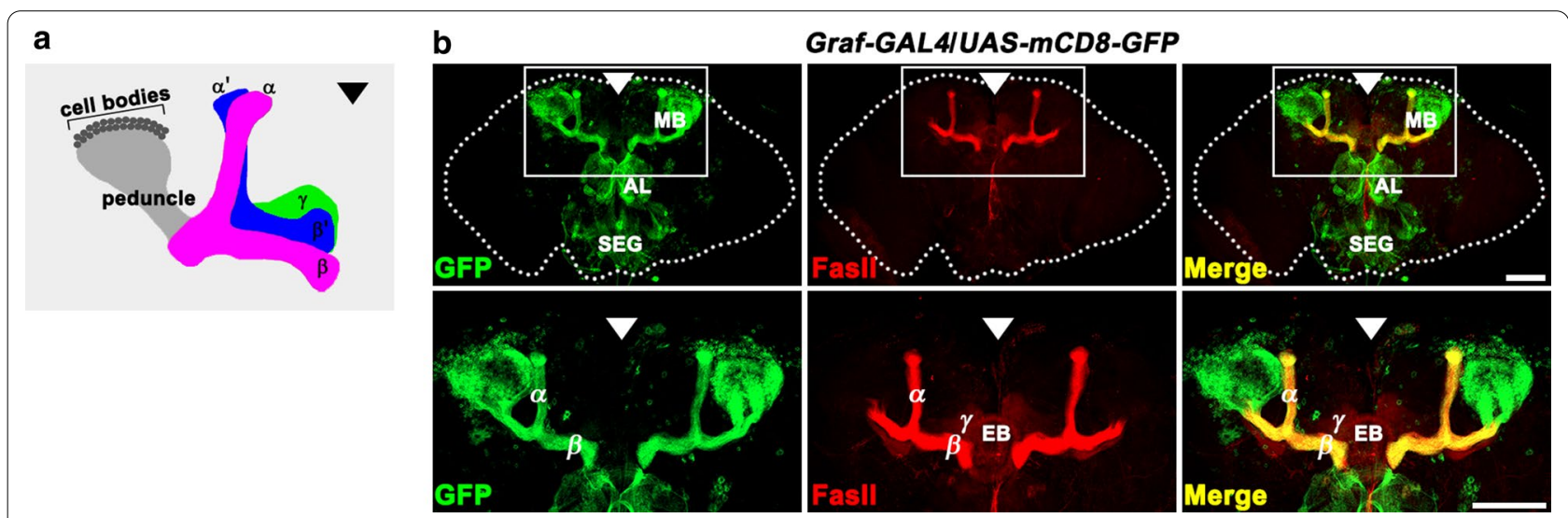

Fig. 1 Graf promoter-driven expression of mCD8-GFP in adult MB neurons. a Schematic representation of the Drosophila adult MB (left side only) showing the axonal projections of $\alpha / \beta, a^{\prime} / \beta^{\prime}$, and $\gamma$ neurons. $\mathbf{b}$ Confocal z-projections of a wild-type adult brain expressing UAS-mCD8-GFP driven by a Graf promotor-GAL4 fusion (Graf-GAL4) and stained with anti-GFP and anti-Fasll antibodies. Bottom panels show high magnification views of areas marked by white boxes to highlight high expression of GFP in Fasll-positive MB a/ $\beta$ axons. Note that the Graf promotor is additionally active in the antennal lobe (AL) and subesophageal ganglion (SEG). EB, ellipsoid body. Arrowheads indicate the brain midline. Scale bars, $100 \mu \mathrm{m}$ 

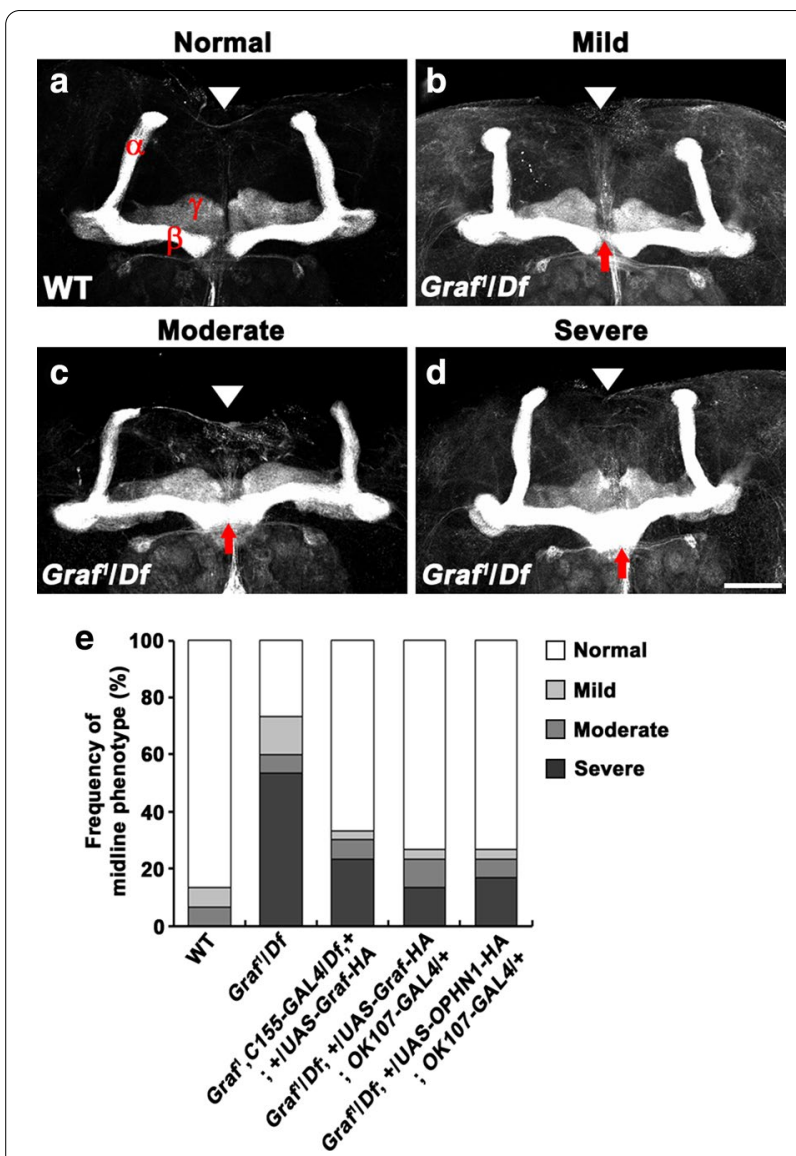

Fig. 2 Mutation in Graf causes MB $\beta$ lobes to over-extend beyond the brain midline. a-d Confocal z-projections of adult brains immunostained with anti-Fasll antibody, which strongly labels the $a$ and $\beta$ lobes and weakly labels the $\gamma$ lobe. a Wild-type (WT) brain with normal MB morphology. The lateral $\beta$ and $\gamma$ lobes from both hemispheres terminate near the brain midline without crossing it. b-d Graf mutant (Graf'/Df) brains exhibiting mild (b), moderate (c), and severe (d) levels of midline crossing by the $\beta$ lobes (arrows). A mild phenotype was defined as a thin band of axon fibers crossing the midline; a moderate phenotype was defined as a substantial fiber bundle crossing the midline that was narrower than the width of the $\beta$-lobe termini; a severe phenotype was defined as a densely stained bundle crossing the midline that was equal to or greater in width than the adjacent $\beta$ lobes [31]. e Quantification of the $\beta$-lobe midline-crossing phenotype in wild-type, Grafl/Df, Graf',C155-GAL4/Df, + ;+/UAS-Graf-HA, Graf'/Df; + /UAS-Graf-HA; OK107-GAL4/+, and Graf'/Df; + /UAS-OPHN1-HA;

OK107-GAL4/ + adult flies ( $n=30$ brains). Arrowheads indicate the brain midline. Scale bar, $50 \mu \mathrm{m}$
However, the projections of the $\alpha$ and $\gamma$ lobes remained intact in Graf $/ D f$ mutant brains (Fig. 2b-d), suggesting a $\beta$-lobe-specific role of Graf.

To test whether loss of Graf function is responsible for the observed $\beta$-lobe midline-crossing phenotype, we pursued rescue experiments by expressing hemagglutinin (HA)-tagged Graf (UAS-Graf-HA) with the panneuronal driver $C 155-G A L 4$ or the pan-MB neuronal driver OK107-GAL4 in the Graf mutant background. The transgenic expression of Graf-HA significantly reduced the severity of the $\beta$-lobe midline-crossing phenotype (Fig. 2e), demonstrating that Graf is required in $\mathrm{MB}$ neurons to correctly pattern $\beta$-lobe projections. We then examined whether MB-specific expression of human OPHN1 would rescue the $\beta$-lobe phenotype of Graf mutants. Expression of UAS-OPHN1-HA under the control of OK107-GAL4 also significantly ameliorated the $\beta$-lobe midline-crossing phenotype of Graf mutants (Fig. 2e), indicating that human OPHN1 is a functional homolog of Graf.

Because anti-FasII does not label the $\alpha^{\prime}$ and $\beta^{\prime}$ lobes and only weakly stains the $\gamma$ lobe, we also assessed the structure of wild-type and Graf mutant MBs by expressing UAS-mCD8-GFP using GAL4 drivers specific for MB $\alpha / \beta$ (c739-GAL4), $\alpha^{\prime} / \beta^{\prime}(c 305 a-G A L 4)$, or $\gamma(1471-G A L 4)$ neurons [23]. In wild-type adult flies carrying UAS$m C D 8-G F P$ and $c 739-G A L 4$, GFP-positive axons completely overlapped FasII immunostaining in the dorsal $\alpha$ and medial $\beta$ lobes (Fig. 3a). Graf $f^{1} / D f$ brains carrying $U A S-m C D 8-G F P$ and $c 739-G A L 4$ showed GFP-positive $\beta$ lobes crossing the midline, though their GFP-labeled $\alpha$ lobes were morphologically normal (Fig. 3a). The penetrance and expressivity of the $\beta$-lobe midline-crossing phenotype determined by GFP staining were not significantly different from those determined by anti-FasII immunohistochemistry. Importantly, the overall structures of the UAS-mCD8-GFP/c305a-GAL4-labeled $\alpha^{\prime}$ and $\beta^{\prime}$ lobes and the UAS-mCD8-GFP/1471-GAL4labeled $\gamma$ lobes remained normal in Grafl $/ D f$ mutant brains (Fig. 3b, c), supporting the notion that the function of Graf in MB development is $\beta$ lobe specific.

\section{The $\beta$-lobe midline-crossing phenotype of Graf mutant MBs develops during metamorphosis}

$\mathrm{MB} \alpha / \beta$ neurons are generated and develop their axonal projections into the $\alpha$ and $\beta$ lobes during the early pupal

(See figure on next page.)

Fig. 3 Loss of Graf selectively disrupts $\beta$-lobe morphology. Representative confocal z-projections of adult wild-type and Graf ${ }^{l} / D f$ brains expressing UAS-mCD8-GFP under the control of MB cell-type specific GAL4 drivers to label all $a / \beta(\mathbf{a} ; c 739), a^{\prime} / \beta^{\prime}(\mathbf{b} ; c 305 a)$, and $\gamma(\mathbf{c} ; 1471)$ neurons $(n=30$ brains). Brains were double stained with anti-GFP (green) and anti-Fasll (red) antibodies. Note that $\beta$ lobes in Graf mutants display midline crossing defects (arrows), whereas the $a, a^{\prime}, \beta^{\prime}$, and $\gamma$ lobes show no obvious morphological defect. Arrowheads indicate the brain midline. Scale bar, $50 \mu m$ 


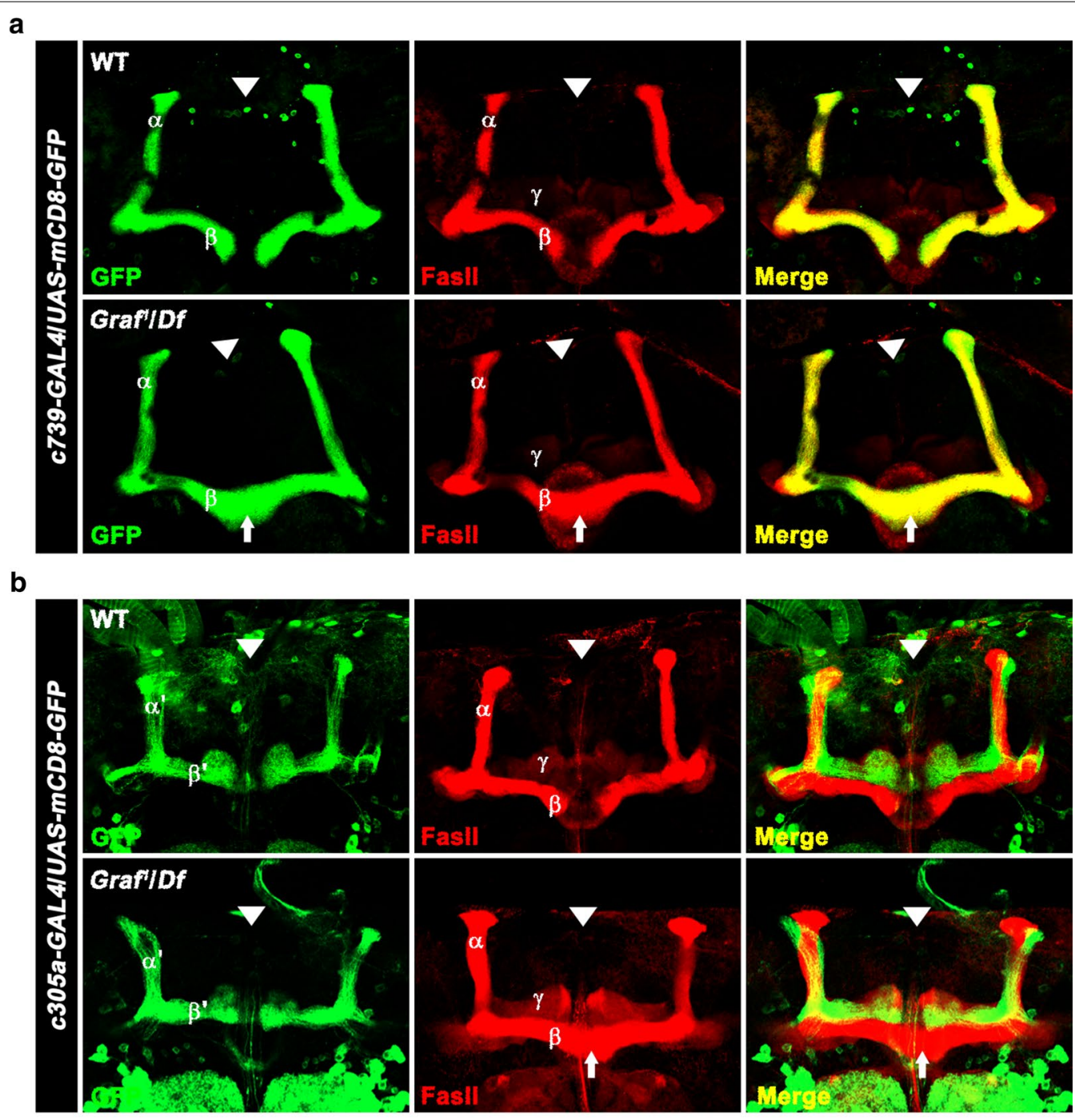

c

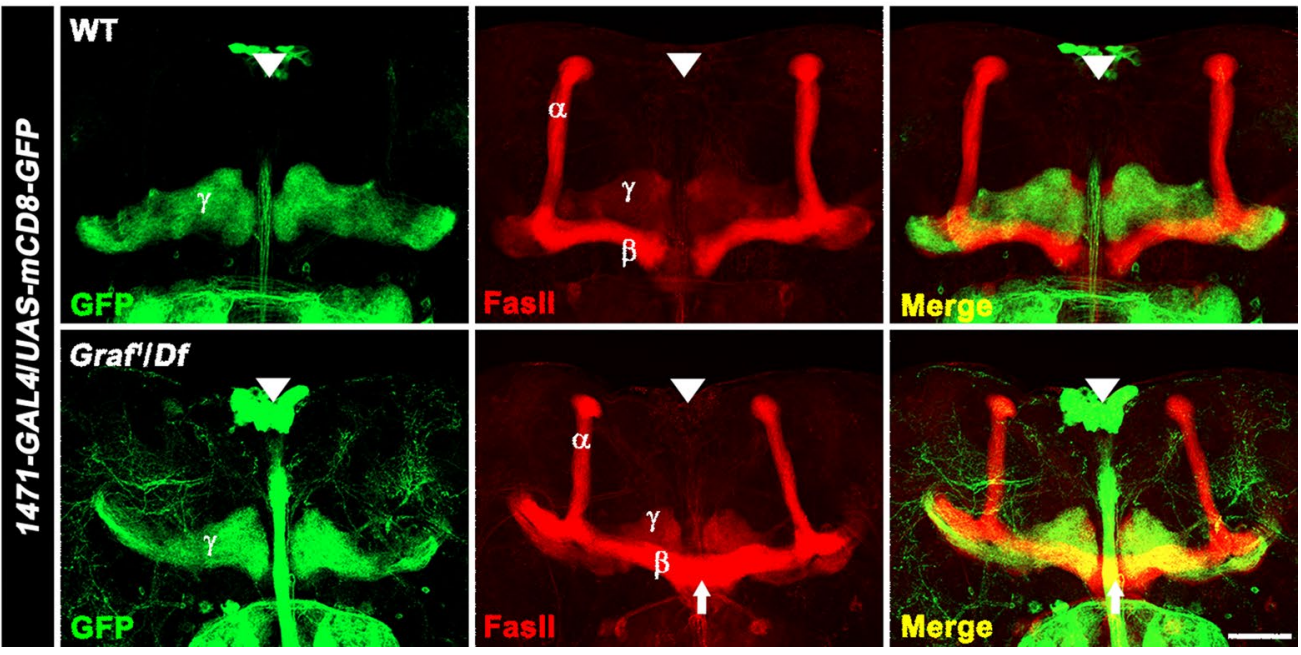




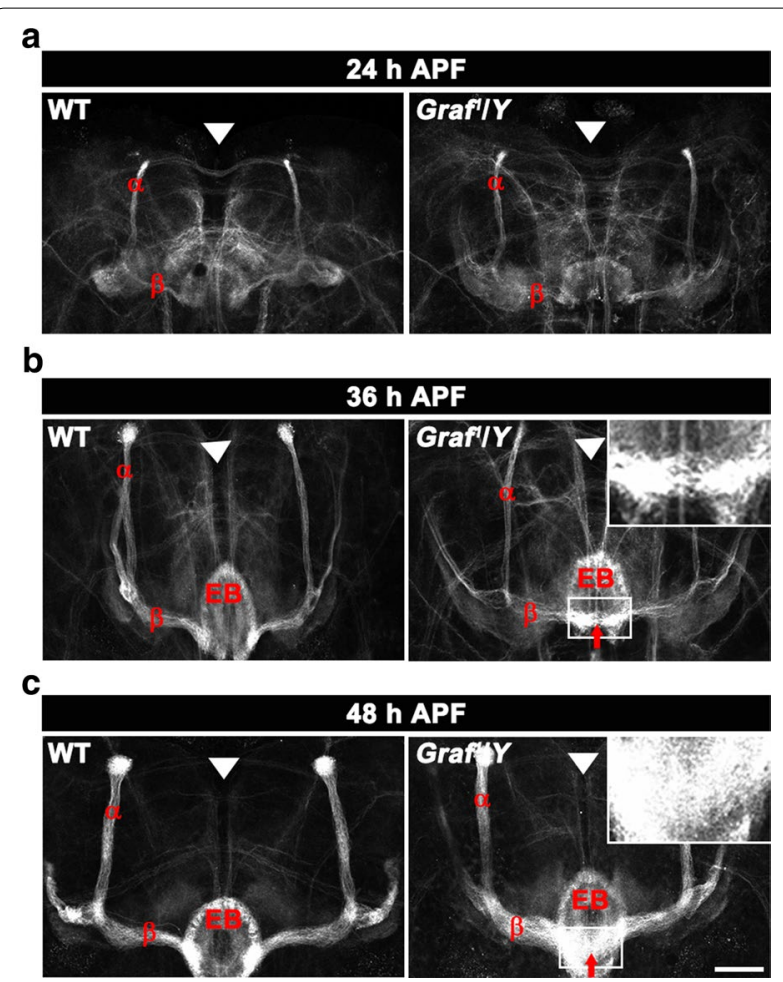

Fig. 4 The $\beta$-lobe midline-crossing phenotype in Graf mutants develops during pupal development. Representative confocal $z$-projections of anti-Fasll-labeled $\alpha$ and $\beta$ lobes from wild-type and Graf'/Df pupae at indicated stages ( $n=24$ brains). a At 24 h APF, the medial $\beta$ lobes extend toward the brain midline (arrowheads) in both wild-type and Graf mutant flies. At this developmental stage, the $a$ and $\beta$ lobes are very thin compared with their mature morphology. b At $36 \mathrm{~h}$ APF, $\beta$-lobe termini project onto the ellipsoid body (EB) without crossing the brain midline in the wild-type fly, whereas $\beta$-lobe fibers in the Graf mutant brain have crossed the midline (arrow). c At 48 h APF, MB lobes have thickened, and the $\beta$-lobe midline-crossing phenotype (arrow) can be seen more clearly. The insets show magnified regions of the midline. Scale bar, $50 \mu \mathrm{m}$

period [28]. To detect the onset of the $\beta$-lobe midlinecrossing phenotype, we analyzed Graf mutant brains at early pupal stages via FasII immunostaining. In wild-type pupae at $24 \mathrm{~h}$ after puparium formation (APF), FasII labeling detected the nascent $\alpha$ and $\beta$ lobes as thin dorsally and medially projecting bundles, respectively (Fig. 4a). At this developmental stage, the tips of the $\beta$ lobes closely approached but did not cross the brain midline (Fig. 4a). The overall morphology of the $\alpha$ and $\beta$ lobes was similar at $36 \mathrm{~h} \mathrm{APF}$ and $48 \mathrm{~h} \mathrm{APF,} \mathrm{except} \mathrm{for} \mathrm{an} \mathrm{incremental}$ increase of lobe thickness (Fig. 4b, c). In Graf mutants, the $\alpha$ and $\beta$ lobes appeared as FasII-positive thin bundles with normal wild-type projections at $24 \mathrm{~h} \mathrm{APF} \mathrm{(Fig.} \mathrm{4a),}$ suggesting that axonal development of $\alpha / \beta$ neurons proceeded normally up to this stage. Furthermore, Graf mutant $\alpha$ and $\beta$ lobes showed normal progressive thickening from $24 \mathrm{~h} \mathrm{APF}$ onwards (Fig. 4b, c). However, the $\beta$-lobe midline-crossing phenotype was observed in Graf mutant brains at $36 \mathrm{~h} \mathrm{APF} \mathrm{(19 \% ;} \mathrm{Fig.} \mathrm{4b)} \mathrm{and} \mathrm{was} \mathrm{more}$ pronounced at $48 \mathrm{~h} \mathrm{APF} \mathrm{(30 \% ;} \mathrm{Fig.} \mathrm{4c),} \mathrm{often} \mathrm{leading} \mathrm{to}$ complete fusion of the two contralateral $\beta$ lobes. These data indicate that the $\beta$-lobe midline-crossing phenotype of adult Graf mutants arises from an initial defect of axon extension during metamorphosis.

\section{Graf regulates $\beta$-lobe extension via a cell-autonomous mechanism}

To determine where Graf might act, we knocked down Graf specifically in $\mathrm{MB} \alpha / \beta$ neurons. Expression of a Graf RNA-interference transgene (Graf ${ }^{R N A i}$ ) using the $\alpha / \beta$ neuron-specific $c 739-G A L 4$ driver induced midline crossing of $\beta$ axons in $\sim 50 \%$ of the brains (Fig. $5 \mathrm{a}, \mathrm{b}$ ), supporting the possibility that Graf is required in $\alpha / \beta$ neurons for $\beta$-lobe midline stopping.

To further investigate cell autonomy, we generated single cell Graf mutant clones in the Grafl/ heterozygous background using the MARCM technique [32], in which clones are produced by mitotic recombination and labeled by $\mathrm{mCD} 8-\mathrm{GFP}$ expression. In these experiments, we induced clone formation at the pupal stage to preferentially target $\alpha / \beta$ neurons. Similar to that observed for wild-type brains, a small minority of $\mathrm{Graf}^{1 /}+$ heterozygous brains showed mild $\beta$-lobe midline-crossing phenotypes. We therefore quantified clonal axon phenotypes only in $\mathrm{Graf}^{1} /+$ brains with normal $\beta$-lobe morphology, revealing $21 \%$ of Graf $^{1}$ mutant clones exhibited a $\beta$-axon midline-crossing phenotype (Fig. $5 \mathrm{c}$ ). In control experiments, none of the wild-type clones in the wild-type background displayed defects in $\beta$-axon extension (Fig. 5c). These findings support the model that Graf functions cell autonomously to prevent $\beta$-lobe overextension.

\section{Graf prevents $\beta$-lobe overextension by inhibiting EGFR signaling}

How does Graf regulate the extension of the tips of the MB $\beta$ lobe? Graf plays an essential role in glycosylphosphatidylinositol-enriched endocytic compartment (GEEC) endocytosis [19]. In Drosophila blood cells (hemocytes), Graf-mediated GEEC endocytosis downregulates EGFR cell surface expression to negatively regulate EGFR-MAPK signaling [19], which plays a role in $\mathrm{MB}$ development [33]. We therefore hypothesized that Graf might regulate $\beta$-lobe development by way of EGFR signaling. To test this, we examined phosphorylated ERK (pERK), a readout of EGFR-MAPK activation [34], by western blot analysis of adult brain lysates. We observed a 1.8-fold-increase in pERK levels in hemizygous Graf ${ }^{1}$ brains relative to wild-type controls (Fig. 6a, b). Immunohistochemistry on adult brains also revealed increased 

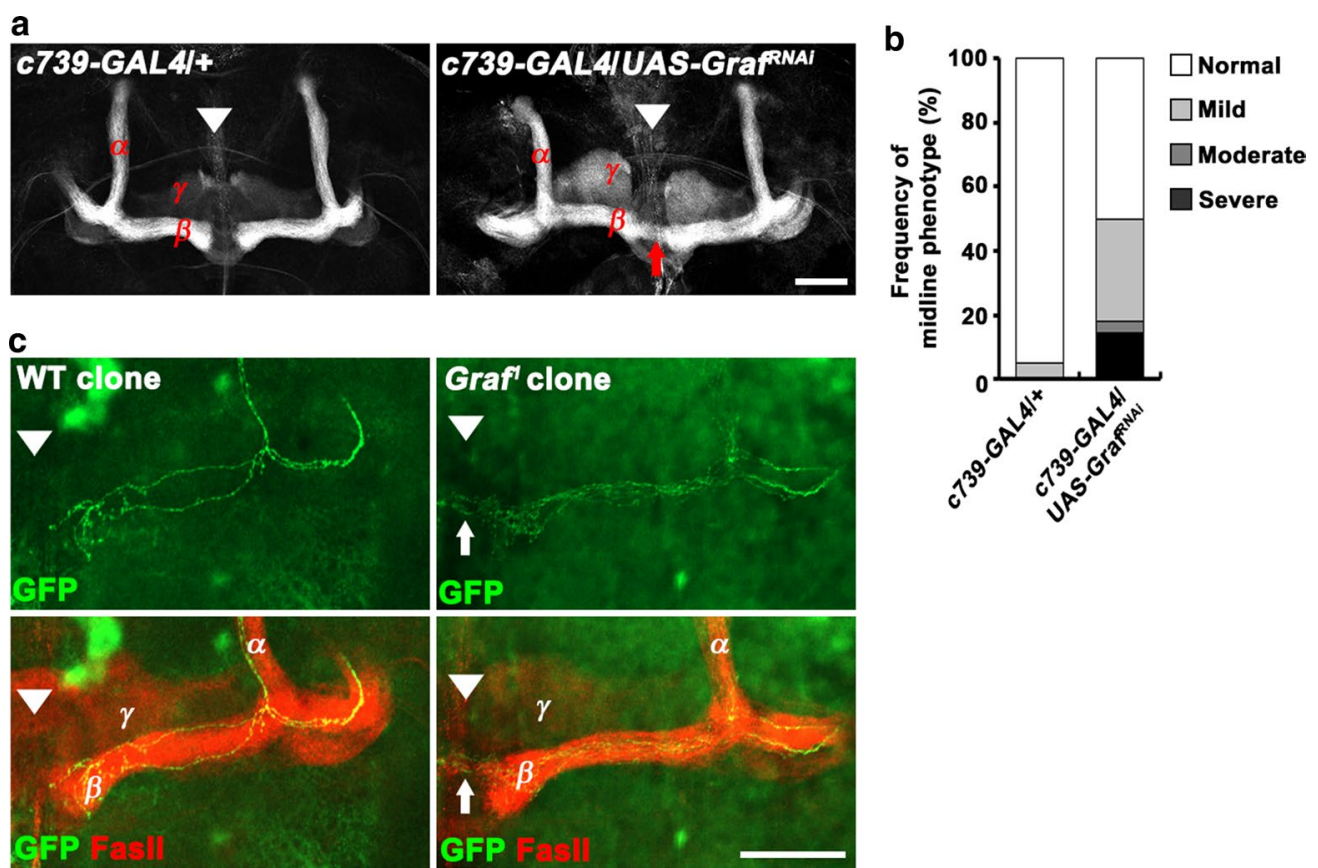

Fig. 5 Graf is expressed in $M B$ a/ $\beta$ neurons and acts cell autonomously to regulate $\beta$-lobe midline stopping. a, b Knocking down Graf expression specifically in $\mathrm{MB}$ a/ $\beta$ neurons induces midline crossing of $\beta$-lobe axons. a Confocal z-projections of c739-GAL4/ + and c739-GAL4/UAS-Graf ${ }^{\text {NNAi }}$ adult brains stained with anti-Fasll antibody. $\mathbf{b}$ Quantification of the $\beta$-lobe midline-crossing phenotype. $c 739-G A L 4 /+, n=20$ brains; c739-GAL4/UAS-Graf ${ }^{\text {PNAi }}, n=28$ brains. c Confocal z-projections of wild-type and Graf mutant MARCM clones labeled with UAS-mCD8-GFP driven by OK107-GAL4. Brains were co-stained with anti-Fasll to label MB a and $\beta$ lobes. Genotypes: hs-FLP,tubP-GAL80,FRT19A/FRT19A; UAS-mCD8-GFP/+; OK107-GAL4/ + (wild-type clones) and hs-FLP,tubP-GAL80,FRT19A/Graf',FRT19A; UAS-mCD8-GFP/ + ; OK107-GAL4/+ (Graf' clones). Note that Graf mutant $\beta$ axons in a Grafl/ + heterozygous brain exceed the $\beta$-lobe region, further extending to the contralateral side. Arrowheads indicate the brain midline. Arrows indicate $\beta$-axons crossing the midline. Scale bars, $50 \mu \mathrm{m}$

pERK levels in Graf mutant MB neurons, which were labeled by OK107-GAL4/UAS-NLS-mCherry (Fig. 6c), confirming that Graf negatively regulates EGFR signaling in $\mathrm{MB}$ neurons.

We also examined the effect of constitutive activation of EGFR signaling on $\beta$-lobe extension. Overexpression of a UAS transgene of constitutively active EGFR $\left(\right.$ EGFR $^{\mathrm{CA}}$ ) using OK107-GAL4 led to $\beta$-lobe overextension in the wild-type background, recapitulating the Graf null phenotype (Fig. 6d, e, j). This phenotypic similarity suggests that Graf acts through an EGFR signaling pathway to facilitate $\beta$-lobe midline stopping.

We then investigated whether reduction or loss of EGFR-MAPK pathway components suppresses the $\beta$-lobe defect of Graf mutants. Loss of one copy of Egfr or the MAPK gene rolled $(r l)$, which had no effect on $\beta$-lobe extension in the wild-type background, significantly suppressed the $\beta$-lobe midline-crossing phenotype of Graf ${ }^{l}$ hemizygotes (Fig. $6 f-h, j$ ). Moreover, the $\beta$-lobe defect of Graf was further suppressed by removing both copies of $r l$ (Fig. 6i, j), indicating that $\beta$-lobe midline crossing in Graf mutants depends on the level of EGFR signaling.
Combined with the effect of EGFR ${ }^{\mathrm{CA}}$ on $\beta$-lobe development, these findings are consistent with the model in which Graf prevents $\beta$-lobe overextension by downregulating EGFR-MAPK signaling.

Next, we examined the impact of Graf knockdown on the endocytic removal of cell surface EGFRs in BG2c2 neuronal cells. We transiently transfected a FlagEGFR construct into control and Graf-knockdown cells (Fig. 7a), and assessed their ability to internalize cell surface Flag-EGFRs in a receptor internalization assay. In this assay, cell surface Flag-EGFRs in live cells were prelabeled with anti-Flag antibody at $4{ }^{\circ} \mathrm{C}$ in the absence or presence of HA-tagged secreted Spi (sSpi-HA), an EGFR ligand. Cells were then incubated at room temperature for $5 \mathrm{~min}$ to allow endocytosis to occur, and the cell surface and internalized pools of the prelabeled Flag-EGFRs were labeled sequentially with green- and red-fluorescent secondary antibodies under nonpermeant and permeant conditions. In unstimulated control cells, we observed a low background level of internalized Flag-EGFRs (Fig. 7b). However, Spi stimulation caused cell surface Flag-EGFRs to rapidly internalize into 

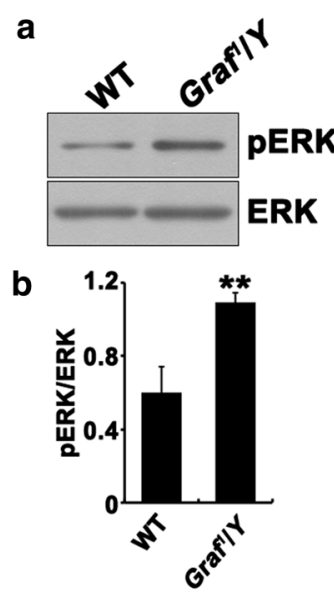

c
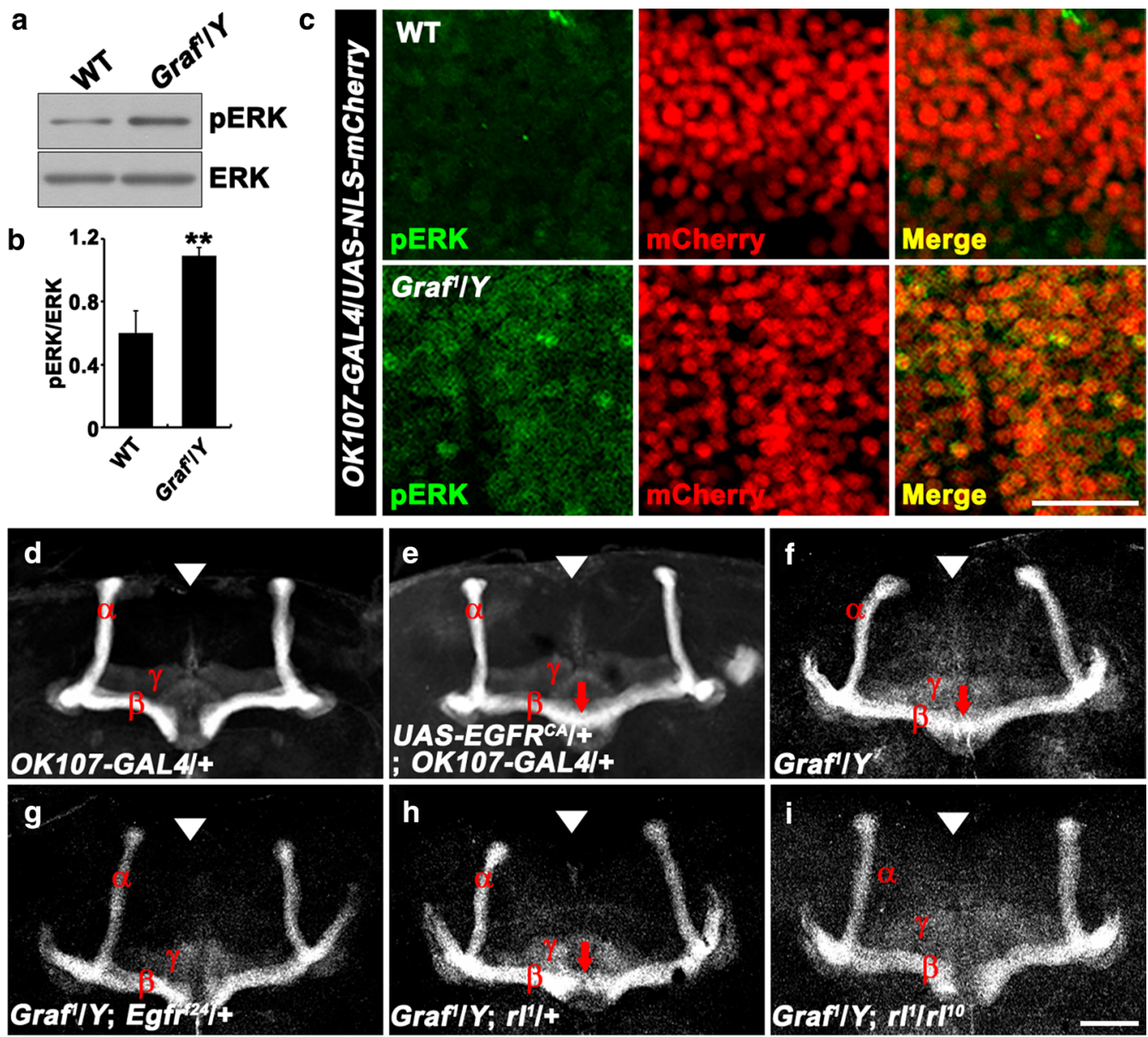

j

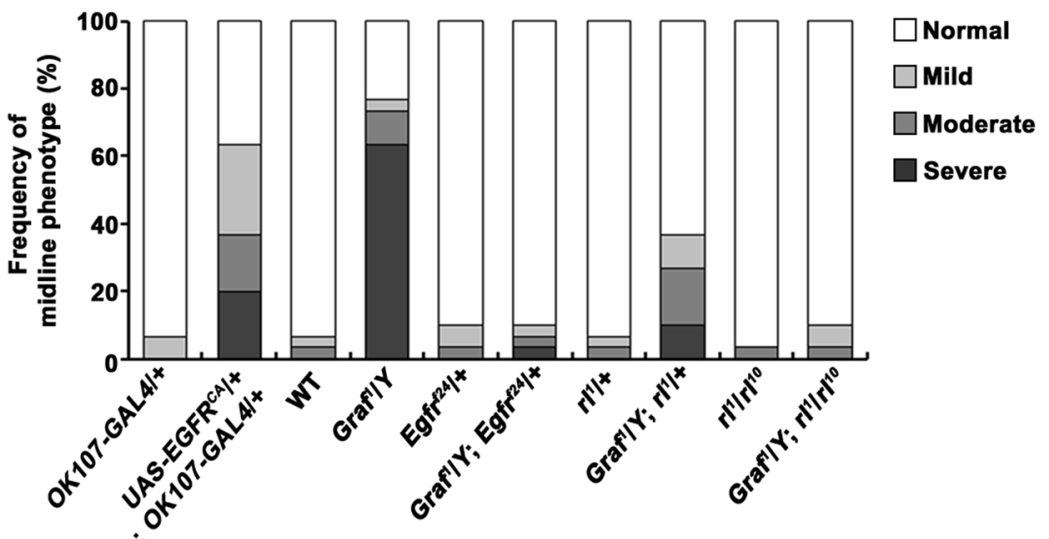

Fig. 6 Genetic interactions for the $\beta$-lobe overextension defect between Graf and EGFR signaling pathway components. a Western blot analysis of brain lysates prepared from wild-type and Graf $/ Y$ adult brains, using anti-pERK and anti-ERK antibodies. $\mathbf{b}$ Normalized ratios of pERK to ERK from three separate blots ( ${ }^{* *} P<0.01$; Student's $t$ test). $\mathbf{c}$ Single confocal sections showing the $p E R K$ immunoreactivity in the MB neurons of UAS-NLS-mCherry/+;OK107-GAL4/ + (wild type) and Graf'/Y; UAS-NLS-mCherry/ +;OK107-GAL4/ + (Graf'/Y) adult brains. Scale bar, 20 m. d-i Sample confocal z-projections of anti-Fasll-stained adult brains in OK107-GAL4/+ (d), UAS-EGFR CA / ; OK107-GAL4/+ (e), Grafl/Y (e), $\mathrm{Graf}^{1} / Y_{;} \mathrm{Egfr}^{\mathrm{f} 24} /+(\mathbf{g}), \mathrm{Graf}^{1} / Y_{;} \mathrm{rl}^{1} /+(\mathbf{h})$, and $\mathrm{Graf}^{\prime} / Y_{;} r l^{1} / \mathrm{rl}^{10}$ (i) flies. Arrowheads indicate the brain midline. Note that reduction or loss of EGFR signaling pathway components suppresses $\beta$-lobe overextension (arrows) in Graf mutant brains. Scale bar, $50 \mu$ m. $\mathbf{j}$ Quantification of the $\beta$-lobe midline-crossing phenotype in adult brains of indicated genotypes ( $n=30$ brains) 


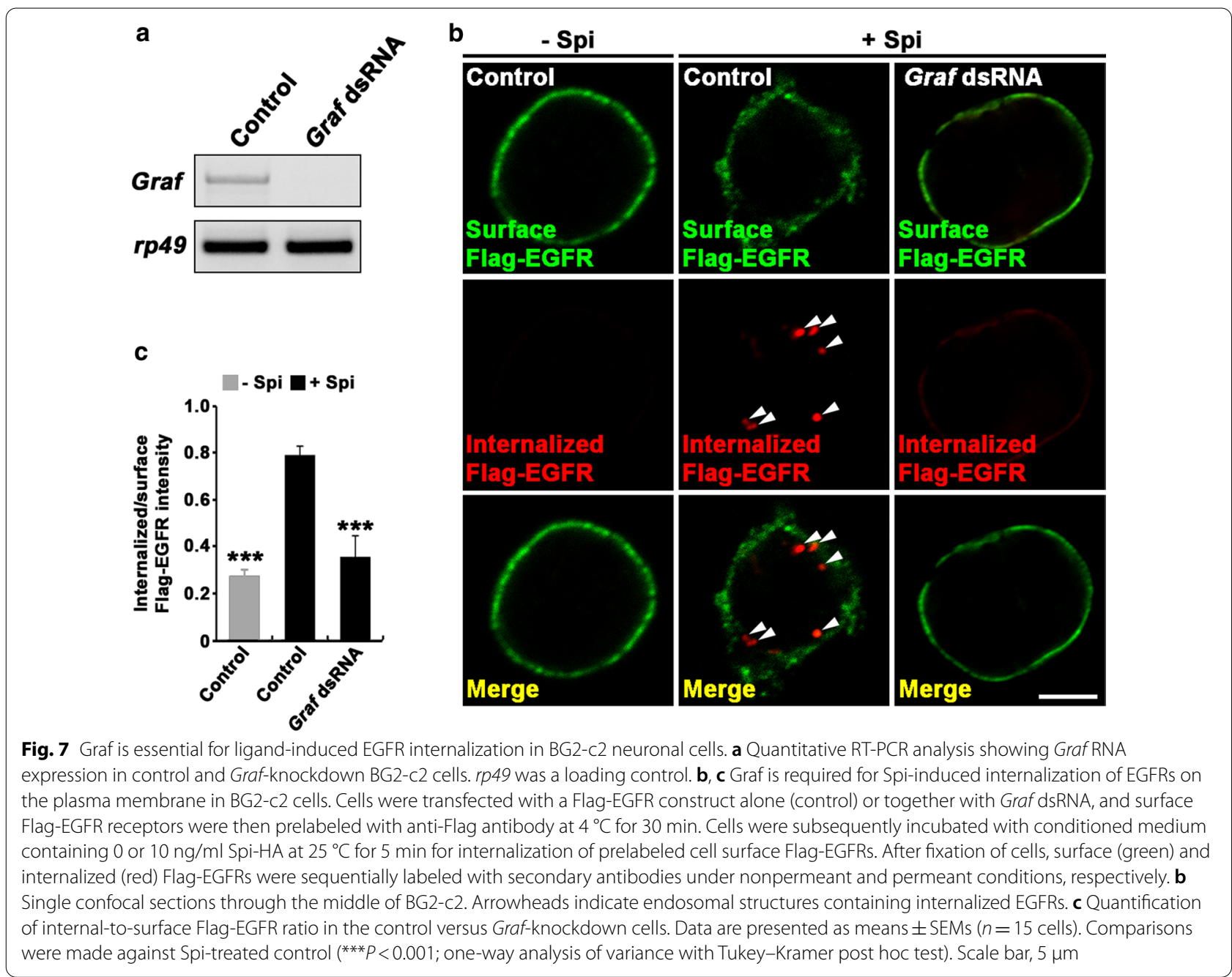

intracellular small punctae near the plasma membrane that may represent early endosomes (Fig. $7 \mathrm{~b}$ ). The ratio of internalized to surface Flag-EGFR levels was significantly increased in Spi-stimulated cells relative to that in unstimulated controls (Fig. 7c). Importantly, this Spiinduced EGFR internalization was completely abrogated by Graf knockdown (Fig. 7c). As Graf-dependent GEEC endocytosis is essential for EGFR degradation and signal attenuation [19], these results further support the model that Graf facilitates $\beta$-lobe midline stopping by downregulating EGFR signaling.

\section{Loss of Graf impairs olfactory long-term memory}

As the MB is a key center for learning and memory and cognitive impairment is a hallmark of ID, we tested the learning and memory abilities of hemizygous $\mathrm{Graf}^{l}$ mutants in an aversive olfactory learning assay [35]. In this assay, flies were trained to associate an electric shock with an air flow containing $\mathrm{MCH}$ or OCT. Neither wildtype nor Graf mutant flies showed a behavioral preference for either odor before training. Trained flies were then tested for their ability to remember the electric shock-associated odor in a T-maze, where both odors were delivered simultaneously in the absence of electric shock. Immediately after training $(0 \mathrm{~h})$, Graf mutant flies showed normal avoidance of the electric shockassociated odor, similarly to the wild-type flies (Fig. 8a), suggesting that olfactory learning is normal in Graf mutants. In addition, short-term $(1 \mathrm{~h})$ and intermediateterm (3 h) memories were also normally formed in Graf mutants (Fig. 8b, c). By contrast, Graf mutants displayed significantly reduced memory performance at $24 \mathrm{~h}$ after training (Fig. 8d). This phenotype of Graf mutants was significantly rescued by expressing $U A S-G r a f-H A$ using OK107-GAL4 (Fig. 8d). These data indicate that the loss of Graf selectively impairs long-term olfactory memory. 

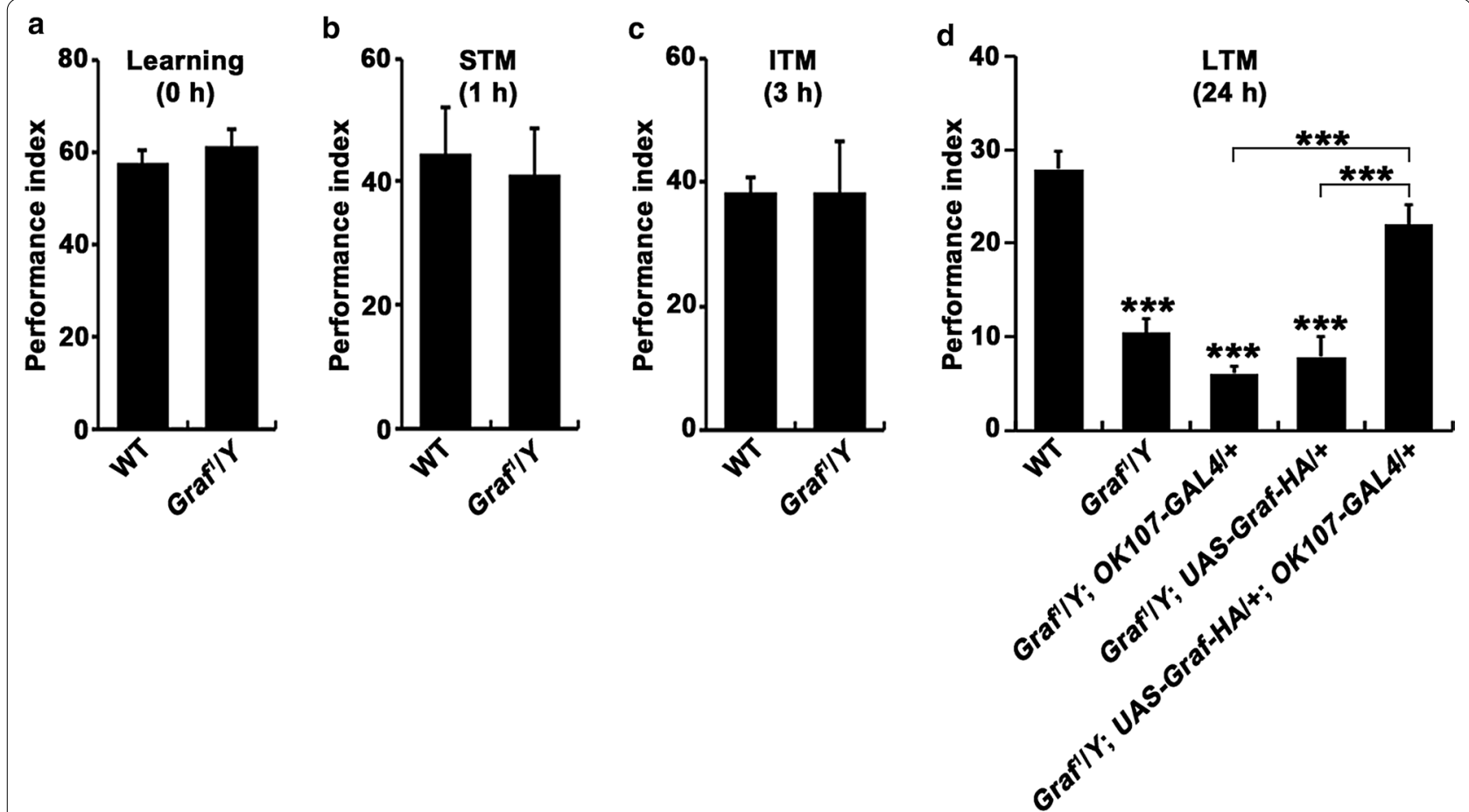

Fig. 8 Long-term memory is defective in Graf mutants. Wild-type, Graf'/Y, Graf'/Y; OK107-GAL4/+, Grafl/Y; UAS-Graf-HA/+, and Graf'/Y; UAS-Graf-HA/ +;OK107-GAL4/ + flies were tested for learning immediately after a single training session (a) as well as for short-term (1 h) (b), intermediate-term (3 h) (c), and long-term (24 h) (d) memory. Note that Graf $/ Y$ mutants are specifically defective in long-term memory. Data are presented as means \pm SEMs ( $n=9$ independent experiments). All comparisons are made against wild-type unless indicated $\left({ }^{* * *} P<0.001 ;\right.$ one-way analysis of variance with Tukey-Kramer post hoc test)

\section{Discussion}

Here we revealed that Drosophila Graf is required for proper development of the $\mathrm{MB}$, a primary brain center in the fly for olfactory learning and memory [36]. In normal MB development, the lateral $\beta$ lobe terminates near the brain midline and rarely crosses it. However, axons of the $\beta$ lobe in Graf mutants overextend beyond the midline, often resulting in apparent fusion of the two contralateral $\beta$ lobes. Our evidence suggests that EGFR-MAPK signaling is involved in this Graf phenotype. First, levels of pERK are increased in Graf mutant MB neurons relative to wild-type controls, implying that Graf acts to downregulate EGFR-MAPK signaling. Second, MB neuron-specific expression of constitutively active EGFR also produces a $\beta$-lobe midline-crossing defect. Third, the midline-crossing phenotype of Graf mutants is suppressed by reducing the level of either Egfr or the MAPK gene $r l$. Finally, Graf mediates ligand-induced removal of cell surface EGFR in BG2-c2 neuronal cells. We previously showed that Graf-dependent internalization of EGFR is indispensable for its degradation and signal attenuation [19]. Thus, our present findings suggest that Graf downregulates EGFR-MAPK signaling to stop the $\beta$ lobe from crossing the midline.
During MB development, the earlier-born $\alpha^{\prime} / \beta^{\prime}$ and $\gamma$ neurons establish lateral pathways that $\beta$ axons can then follow [28, 37, 38]. However, the midline-crossing phenotype induced by Graf mutations or constitutive activation of EGFR signaling is restricted to the $\beta$ lobe, with proper midline stopping of the $\beta^{\prime}$ and $\gamma$ lobes. This result suggests that the extension of $\beta, \beta^{\prime}$, and $\gamma$ lobes is independently controlled by lobe-specific mechanisms. Consistent with this idea, we found that the activity of the Graf promoter is highly specific for $\alpha / \beta$ neurons in the MB. Furthermore, a Graf-knockdown experiment and mosaic analysis demonstrated a cell-autonomous role for Graf in $\alpha / \beta$ neurons for proper stopping of the $\beta$ lobe at the brain midline.

We also found that loss of Graf causes a specific defect in olfactory long-term memory, possibly paralleling cognitive impairments caused by OPHN1 loss in humans. It is generally accepted that the $\alpha / \beta$ neurons are necessary for olfactory long-term memory, whereas the $\alpha^{\prime} / \beta^{\prime}$ and $\gamma$ neurons mediate intermediate-and short-term memory, respectively [39-42]. Therefore, in Graf mutants, $\beta$-lobe midline crossing may account for the long-term memory deficit. Interestingly, simultaneous defects in $\beta$-lobe midline stopping and olfactory long-term memory are also caused by 
mutations in $d F m r 1$ [31, 43], which encodes an ortholog of the ID-associated protein FMRP [44]. This common feature of Graf and dFmr1 supports the role of the $\beta$ lobe in long-term memory and warrants future investigation of potential links between these two ID-associated genes.

Previous studies in mammals have implicated OPHN1 in the regulation of synaptic structure, function, and plasticity $[9,13,14,16,17]$. The present study uncovered a role for Graf in regulating axonal projections of memory-forming $\alpha / \beta$ neurons and provides a basis for further investigations into the neurodevelopmental roles of OPHN1 to gain additional insights into the pathogenesis of ID.

\section{Abbreviations \\ APF: After puparium formation; EGFR: Epidermal growth factor receptor; Graf: GTPase regulator associated with focal adhesion kinase-1; GAP: GTPase- activating protein; ID: Intellectual disability; MAPK: Mitogen-activated protein kinase; MB: Mushroom body; MCH: 4-Methylcyclohexanol; OCT: 3-Octanol; OPHN1: Oligophrenin-1; Spi: Spitz.}

\section{Acknowledgements}

The authors thank Dr. Ernst Hafen and the Bloomington Stock Center for providing the fly strains used in this study.

\section{Authors' contributions}

SK and SL designed the study. SK, JK, and SP performed the experiments and analyzed the data. JP analyzed the data. SK and SL wrote the manuscript. All authors read and approved the final manuscript.

\section{Funding}

This work was supported by grants from the National Research Foundation of Korea (2017M3C7A1025368 and 2019R1A2C2089437).

\section{Availability of data and materials}

Data sharing not applicable to this article as no datasets were generated or analysed during the current study.

\section{Declarations}

Ethics approval and consent for participation

Not applicable.

\section{Consent for publication}

Not applicable.

\section{Competing interests}

The authors declare that they have no competing interest.

\section{Author details}

'Department of Cell and Developmental Biology and Dental Research Institute, Seoul National University, Seoul 08826, Republic of Korea. ${ }^{2}$ Department of Brain and Cognitive Sciences, Seoul National University, Seoul 08826 Republic of Korea. ${ }^{3}$ Department of Physiology, College of Medicine, Korea University, Seoul 02841, Republic of Korea.

Received: 1 December 2020 Accepted: 15 April 2021

Published online: 23 April 2021

\section{References}

1. Maulik PK, Mascarenhas MN, Mathers CD, Dua T, Saxena S. Prevalence of intellectual disability: a meta-analysis of population-based studies. Res Dev Disabil. 2011;32:419-36.
2. Kochinke K, Zweier C, Nijhof B, Fenckova M, Cizek P, et al. Systematic phenomics analysis deconvolutes genes mutated in intellectual disability into biologically coherent modules. Am J Hum Genet. 2016;98:149-64.

3. Billuart P, Bienvenu T, Ronce N, des Portes V, Vinet MC, et al. Oligophrenin-1 encodes a rhoGAP protein involved in X-linked mental retardation. Nature. 1998;392:923-6.

4. Bienvenu T, Der-Sarkissian H, Billuart P, Tissot M, Des Portes V, et al. Mapping of the $X$-breakpoint involved in a balanced $X ; 12$ translocation in a female with mild mental retardation. Eur J Hum Genet. 1997:5:105-9.

5. Bergmann C, Zerres K, Senderek J, Rudnik-Schoneborn S, Eggermann T, et al. Oligophrenin 1 (OPHN1) gene mutation causes syndromic X-linked mental retardation with epilepsy, rostral ventricular enlargement and cerebellar hypoplasia. Brain. 2003;126:1537-44.

6. des Portes V, Boddaert N, Sacco S, Briault S, Maincent K, et al. Specific clinical and brain MRI features in mentally retarded patients with mutations in the Oligophrenin-1 gene. Am J Med Genet A. 2004;124A:364-71.

7. Philip N, Chabrol B, Lossi AM, Cardoso C, Guerrini R, et al. Mutations in the oligophrenin-1 gene (OPHN1) cause X linked congenital cerebellar hypoplasia. J Med Genet. 2003:40:441-6.

8. Zanni G, Saillour Y, Nagara M, Billuart P, Castelnau L, et al. Oligophrenin 1 mutations frequently cause $X$-linked mental retardation with cerebellar hypoplasia. Neurology. 2005;65:1364-9.

9. Khelfaoui M, Denis C, van Galen E, de Bock F, Schmitt A, et al. Loss of $X$-linked mental retardation gene oligophrenin 1 in mice impairs spatial memory and leads to ventricular enlargement and dendritic spine immaturity. J Neurosci. 2007;27:9439-50.

10. Doherty GJ, McMahon HT. Mechanisms of endocytosis. Annu Rev Biochem. 2009;78:857-902.

11. Peter BJ, Kent HM, Mills IG, Vallis Y, Butler PJ, et al. BAR domains as sensors of membrane curvature: the amphiphysin BAR structure. Science. 2004:303:495-9.

12. Fauchereau F, Herbrand U, Chafey P, Eberth A, Koulakoff A, et al. The RhoGAP activity of OPHN1, a new F-actin-binding protein, is negatively controlled by its amino-terminal domain. Mol Cell Neurosci. 2003:23:574-86.

13. Govek EE, Newey SE, Akerman CJ, Cross JR, Van der Veken L, et al. The $X$-linked mental retardation protein oligophrenin-1 is required for dendritic spine morphogenesis. Nat Neurosci. 2004;7:364-72.

14. Nadif Kasri N, Nakano-Kobayashi A, Van Aelst L. Rapid synthesis of the X-linked mental retardation protein OPHN1 mediates mGluR-dependent LTD through interaction with the endocytic machinery. Neuron. 2011:72:300-15.

15. Nakano-Kobayashi A, Kasri NN, Newey SE, Van Aelst L. The Rho-linked mental retardation protein OPHN1 controls synaptic vesicle endocytosis via endophilin A1. Curr Biol. 2009;19:1133-9.

16. Khelfaoui M, Pavlowsky A, Powell AD, Valnegri P, Cheong KW, et al. Inhibition of RhoA pathway rescues the endocytosis defects in oligophrenin 1 mouse model of mental retardation. Hum Mol Genet. 2009;18:2575-83.

17. Nadif Kasri N, Nakano-Kobayashi A, Malinow R, Li B, Van Aelst L. The Rho-linked mental retardation protein oligophrenin-1 controls synapse maturation and plasticity by stabilizing AMPA receptors. Genes Dev. 2009;23:1289-302.

18. Govek EE, Newey SE, Van Aelst L. The role of the Rho GTPases in neuronal development. Genes Dev. 2005;19:1-49.

19. Kim S, Nahm M, Kim N, Kwon Y, Kim J, et al. Graf regulates hematopoiesis through GEEC endocytosis of EGFR. Development. 2017;144:4159-72.

20. Heisenberg M. Mushroom body memoir: from maps to models. Nat Rev Neurosci. 2003:4:266-75.

21. Lin DM, Goodman CS. Ectopic and increased expression of Fasciclin II alters motoneuron growth cone guidance. Neuron. 1994;13:507-23.

22. Connolly JB, Roberts IJ, Armstrong JD, Kaiser K, Forte M, et al. Associative learning disrupted by impaired Gs signaling in Drosophila mushroom bodies. Science. 1996;274:2104-7.

23. Aso Y, Grübel K, Busch S, Friedrich AB, Siwanowicz I, et al. The mushroom body of adult Drosophila characterized by GAL4 drivers. J Neurogenet. 2009:23:156-72.

24. Wu JS, Luo L. A protocol for mosaic analysis with a repressible cell marker (MARCM) in Drosophila. Nat Protoc. 2006:1:2583-9.

25. Brand AH, Perrimon N. Targeted gene expression as a means of altering cell fates and generating dominant phenotypes. Development. 1993:118:401-15. 
26. Kim N, Kim S, Nahm M, Kopke D, Kim J, et al. BMP-dependent synaptic development requires Abi-Abl-Rac signaling of BMP receptor macropinocytosis. Nat Commun. 2019;10:684.

27. Beck CD, Schroeder B, Davis RL. Learning performance of normal and mutant Drosophila after repeated conditioning trials with discrete stimuli. J Neurosci. 2000;20:2944-53.

28. Lee T, Lee A, Luo L. Development of the Drosophila mushroom bodies: sequential generation of three distinct types of neurons from a neuroblast. Development. 1999;126:4065-76.

29. Crittenden JR, Skoulakis EM, Han KA, Kalderon D, Davis RL. Tripartite mushroom body architecture revealed by antigenic markers. Learn Mem. 1998;5:38-51.

30. Strausfeld NJ, Sinakevitch I, Vilinsky I. The mushroom bodies of Drosophila melanogaster: an immunocytological and golgi study of Kenyon cell organization in the calyces and lobes. Microsc Res Tech. 2003;62:151-69.

31. Michel Cl, Kraft R, Restifo LL. Defective neuronal development in the mushroom bodies of Drosophila fragile $X$ mental retardation 1 mutants. J Neurosci. 2004;24:5798-809.

32. Lee T, Luo L. Mosaic analysis with a repressible cell marker for studies of gene function in neuronal morphogenesis. Neuron. 1999;22:451-61.

33. King IF, Eddison M, Kaun KR, Heberlein U. EGFR and FGFR pathways have distinct roles in Drosophila mushroom body development and ethanolinduced behavior. PLoS ONE. 2014;9:e87714

34. Gabay L, Seger R, Shilo BZ. In situ activation pattern of Drosophila EGF receptor pathway during development. Science. 1997;277:1103-6.

35. Tully T, Quinn WG. Classical conditioning and retention in normal and mutant Drosophila melanogaster. J Comp Physiol A. 1985;157:263-77.

36. Davis RL. Traces of Drosophila memory. Neuron. 2011;70:8-19.
37. Billuart P, Winter CG, Maresh A, Zhao X, Luo L. Regulating axon branch stability: the role of 190 RhoGAP in repressing a retraction signaling pathway. Cell. 2001;107:195-207.

38. Reuter JE, Nardine TM, Penton A, Billuart P, Scott EK, et al. A mosaic genetic screen for genes necessary for Drosophila mushroom body neuronal morphogenesis. Development. 2003;130:1203-13.

39. Guven-Ozkan T, Davis RL. Functional neuroanatomy of Drosophila olfactory memory formation. Learn Mem. 2014;21:519-26.

40. Blum AL, Li W, Cressy M, Dubnau J. Short- and long-term memory in Drosophila require CAMP signaling in distinct neuron types. Curr Biol. 2009;19:1341-50.

41. Trannoy S, Redt-Clouet C, Dura JM, Preat T. Parallel processing of appetitive short- and long-term memories in Drosophila. Curr Biol. 2011;21:1647-53.

42. Krashes MJ, Keene AC, Leung B, Armstrong JD, Waddell S. Sequential use of mushroom body neuron subsets during drosophila odor memory processing. Neuron. 2007;53:103-15.

43. Bolduc FV, Bell K, Cox H, Broadie KS, Tully T. Excess protein synthesis in Drosophila fragile $X$ mutants impairs long-term memory. Nat Neurosci. 2008;11:1143-5.

44. Wan L, Dockendorff TC, Jongens TA, Dreyfuss G. Characterization of dFMR1, a Drosophila melanogaster homolog of the fragile $X$ mental retardation protein. Mol Cell Biol. 2000;20:8536-47.

\section{Publisher's Note}

Springer Nature remains neutral with regard to jurisdictional claims in published maps and institutional affiliations.
Ready to submit your research? Choose BMC and benefit from:

- fast, convenient online submission

- thorough peer review by experienced researchers in your field

- rapid publication on acceptance

- support for research data, including large and complex data types

- gold Open Access which fosters wider collaboration and increased citations

- maximum visibility for your research: over $100 \mathrm{M}$ website views per year

At BMC, research is always in progress.

Learn more biomedcentral.com/submissions 